\title{
Weight-management interventions in primary care: a pilot randomised controlled trial
}

Kiran Nanchahal, Joy Townsend, Louise Letley, David Haslam, Kaye Wellings and Andy Haines

\author{
ABSTRACT \\ Background \\ There is a paucity of randomised controlled trials of \\ weight management in primary care. \\ Aim \\ To ascertain the feasibility of a full trial of a nurse-led \\ weight-management programme in general practice. \\ Design of study \\ Factorial randomised control trial. \\ Setting \\ Primary care, UK. \\ Method \\ A total of 123 adults $(80.3 \%$ women, mean age \\ 47.2 years) with body mass index $\geq 27 \mathrm{~kg} / \mathrm{m}^{2}$, recruited \\ from eight practices, were randomised to receive \\ structured lifestyle support $(n=30)$, structured lifestyle \\ support plus pedometer $(n=31)$, usual care $(n=31)$, or \\ usual care plus pedometer $(n=31)$ for a 12-week \\ period. \\ Results \\ A total of 103 participants were successfully followed \\ up. The adjusted mean difference in weight in \\ structured support compared to usual care groups was \\ $-2.63 \mathrm{~kg}(95 \%$ confidence interval $[\mathrm{Cl}]=-4.06$ to \\ $-1.20 \mathrm{~kg}$ ), and for pedometer compared to no \\ pedometer groups it was $-0.11 \mathrm{~kg}(95 \% \mathrm{Cl}=-1.52$ to \\ $1.30 \mathrm{~kg})$. One in three participants in the structured- \\ support groups $(17 / 50,34.0 \%)$ lost $5 \%$ or more of their \\ initial weight, compared to less than one in five $(10 / 53$, \\ $18.9 \%$ ) in usual-care groups; provision of a pedometer \\ made little difference $(14 / 48,29.2 \%$ pedometer; $13 / 55$, \\ $23.6 \%$ no pedometer). Difference in waist \\ circumference change between structured-support and \\ usual-care groups was $-1.80 \mathrm{~cm}(95 \% \mathrm{Cl}=-3.39$ to \\ $-0.20 \mathrm{~cm}$ ), and between the pedometer and no \\ pedometer groups it was $-0.84 \mathrm{~cm}(95 \% \mathrm{Cl}=-2.42$ to \\ $0.73 \mathrm{~cm}$ ). When asked about their experience of study \\ participation, most participants found structured \\ support helpful.

\section{Conclusion} \\ The structured lifestyle support package could make \\ substantial contributions to improving weight- \\ management services. A trial of the intervention in \\ general practice is feasible and practicable. \\ Keywords \\ life style; obesity; overweight; primary health care; \\ weight loss.
}

\section{INTRODUCTION}

Obesity presents an unprecedented public health challenge. ${ }^{1}$ In England, 24\% of adults (aged 16 years and over) were classified as obese in 2007; and around one-fifth of men and one-quarter of women displayed a high risk of obesity-related health problems. ${ }^{2}$ If current trends persist, $36 \%$ of men and $28 \%$ of women aged 21-60 years in England will be obese by $2015 .{ }^{3}$ The cost of treating the consequences of obesity were approximately $£ 1$ billion in 2002 (2.3-2.6\% of NHS expenditure), ${ }^{4}$ and could exceed £3 billion by $2015 .^{3}$ The National Audit Office recommends greater effort to establish an evidence-based methodology directed at overweight, enabling the NHS to adopt a more consistent approach. ${ }^{5}$ It is recognised that reducing obesity, improving diet, and increasing exercise are priorities, ${ }^{6}$ and that primary care provides a unique resource for the identification and management of overweight. ${ }^{4}$

Weight concern among British women is high, but many overweight men are unaware of the problem. ${ }^{7}$ Only half the possible beneficiaries from weight reduction try to lose weight, and few receive health professional advice. Clinician counselling and

K Nanchahal, MSc, senior lecturer; J Townsend, MSc, PhD, emeritus professor of health economics and primary care, London School of Hygiene and Tropical Medicine; L Letley, RN, MSc, senior nurse manager, Medical Research Council General Practice Research Framework, London. D Haslam, MBBS, Watton Place Clinic, Hertfordshire. $K$ Wellings, MSc, professor of sexual and reproductive health; $A$ Haines, $M D$, FRCGP, FFPH, FRCP, FMedSci, professor of public health \& primary care and director, London School of Hygiene and Tropical Medicine, London.

Address for correspondence

Kiran Nanchahal, Public and Environmental Health Research Unit, Department of Public Health and Policy, London School of Hygiene and Tropical Medicine, Keppel Street, London WC1E 7HT.

E-mail: kiran.nanchahal@lshtm.ac.uk

Submitted: 28 June 2008; Editor's response: 19 August 2008; final acceptance: 15 October 2008.

(c)British Journal of General Practice

This is the full-length article of an abridged version published in print. Cite this article as: Br J Gen Pract 2009; DOI: 10.3399/bjgp09X420617. 
treatment for smoking is highly cost-effective, ${ }^{8}$ but primary care remains under-used for obesity control. Few interventions have a sustained impact on weight, hence the need for effective, practical weight-management interventions for primary care.

The current authors have developed a multicomponent intervention as recommended by the Medical Research Council (MRC). ${ }^{9}$ A survey of GPs and nurses was conducted to ascertain current levels of provision: ${ }^{10}$ interviews with health professionals and patients were carried out to ascertain which tools would deliver appropriate care, ${ }^{11}$ and an intervention was developed, based on the findings; this was pre-tested in three practices, and a pilot trial was conducted.

This paper describes the pilot trial of this intervention which comprises: (1) weightmanagement training including use of the National Obesity Forum's CD-ROM, 'Managing Obesity in Primary Care'; (2) structured discussions using a computer program co-developed by a GP-based dietitian; and (3) provision of pedometers. The study evaluated the acceptability of questionnaires, measurement procedures, and the 12-week intervention, to assess the feasibility of a largescale longer-term randomised controlled trial.

\section{METHOD}

\section{Participating general practices}

Eight general practices were recruited from the MRC's General Practice Research Framework of 900 UK practices (9\%) with an average list size of 7500 patients, whose characteristics follow UK population norms. The list size in the study practices ranged from 1700 to 17000 , with one to six GPs in each.

\section{Participants}

Each practice was asked to recruit 16 patients, which was considered feasible within the time frame. Participants were identified by research nurses or doctors, and posters were displayed so patients could self-refer. Inclusion criteria were: age $\geq 18$ years, body mass index $(\mathrm{BMl}) \geq 27 \mathrm{~kg} / \mathrm{m}^{2}$, able to walk for at least 15 minutes, not pregnant, and not on weightloss medication. GPs confirmed patient suitability.

Patients were telephoned and invited for an appointment to assess eligibility and obtain consent. Following full explanation of the study, 123 participants consented and were randomly allocated using a $2 \times 2$ factorial design to: structured support with or without pedometer, and usual care with or without pedometer. Randomisation, stratified by practice, was carried out centrally.

Individual 30-minute appointments were arranged for usual-care participants. Structured-support

\section{How this fits in}

Primary care could have a substantial impact on the increasing prevalence of obesity and its adverse impact on health. The lack of a proven intervention that is feasible in general practice may deter health professionals from providing the appropriate level of support required by overweight and obese patients. This study demonstrates that nurse-led lifestyle support could make a substantial contribution to improving weight-management services, and that a randomised controlled trial of the intervention is feasible in general practice.

group participants were informed they would be contacted 12 weeks later for a 45 minute appointment. To avoid 'contamination', nurses were trained in structured support after they had completed follow-up of the usual-care group.

\section{Nurse training}

Nurses received training in the study protocol and use of pedometers (Model SW-200 Yamax Digiwalker, London, UK) in September 2005. After follow-up of the usual-care patients, they were sent the National Obesity Forum's interactive CD-ROM tool: 'Managing Obesity in Primary Care' with an A3 wall poster of the management algorithm. Additional training in weight management and use of the ProHealthClinical computer package (KasTech Ltd, Cambridge, UK) was provided in January 2006. The structured programme (Appendix 1) included topics for discussion and five clinical counselling constructs: assess, advise, agree, assist, arrange. ${ }^{12}$ Nurses helped patients set realistic weight targets, aiming for a weekly loss of $0.5-1.0 \mathrm{~kg}$; focused on long-term lifestyle changes; used a balanced healthy diet approach tailored to the individual's food preferences using ProHealthClinical suggested physical activity that could be incorporated into patients' everyday lifestyles; used behaviour change techniques including keeping a diary; and offered advice on coping with lapses and high-risk periods, such as Christmas and holidays.

\section{Measurements}

Height, weight, waist circumference, and blood pressure were measured; fasting blood samples were analysed for glucose and lipid profile. The selfcompleted questionnaires included validated measures of self-esteem, ${ }^{13}$ weight-related symptoms, quality of life, anxiety, depression, health status, and demographic details. These measures included the Hospital Anxiety and Depression Scale which performs well in primary care, ${ }^{14}$ and EQ-5D (EuroQol - 5 dimensions) and EQ-VAS (EuroQol Visual Analogue Scale), standardised non-disease-specific instruments for describing and valuing health-related quality of life, as generic measures of health status. ${ }^{15}$ To address the 
key domains relevant to obesity, the Obesity and Weight-Loss Quality of Life instrument was used, which measures the participants' global evaluation of position in life related to weight, weight loss, and weight-loss treatment; and the Weight-Related Symptom Measure, ${ }^{16}$ which focuses on the presence and 'bothersome-ness' of 20 symptoms commonly associated with obesity and obesity treatment. Additional questions were included in the final questionnaire on the experience of study participation. Participants randomised to receive a pedometer were shown how to use it, given a leaflet explaining the significance of 10000 steps a day, and asked to record their steps each day. Nurses completed questionnaires on participants' obesity-related disease, smoking status, and current medication.

\section{Statistical analysis}

Data were entered using Epi-Info ${ }^{\mathrm{TM}}$, and analysed using Stata Statistical Software (version 10), on an intention-to-treat basis, with no substitution for missing data. The study was analysed as a factorial study using analysis of covariance for continuous outcomes. Comparisons between groups were performed using multivariable linear regression models, adjusting each intervention for the other, and for age, sex, and baseline value of the outcome variable. Changes were calculated as final value minus baseline value.

\section{RESULTS}

A total of 123 participants were recruited between October 2005 and March 2006, ages ranged from 22.1 to 68.5 years, weights from 66 to $165 \mathrm{~kg}$, BMI from 27.6 to $50.9 \mathrm{~kg} / \mathrm{m}^{2}$, and waist circumferences from 78 to $157 \mathrm{~cm}$, and $95.8 \%$ (114/119) described themselves as white. Characteristics did not vary significantly by randomisation group (Table 1). Nearly $90 \%(105 / 119,88.2 \%)$ said they were very or extremely motivated to lose weight, $16.1 \%$ (19/118) were 'always on a diet', and $8.4 \%$ (10/119) reported 'always increasing physical activity' to lose weight. Participants wanted to lose an average of $26.0 \mathrm{~kg}$ (standard deviation $=14.0 \mathrm{~kg}$ ), representing $25.0 \%$ of their baseline weight.

Of the 122 participants who attended the baseline visit, $84.4 \%$ (103/122) were successfully followed up (Figure 1). Follow-up did not vary by randomisation group ( $P=0.21$ ) or baseline weight $(P=0.12$ ), although non-completers were younger than completers (mean

Table 1. Characteristics of participants at baseline.

\begin{tabular}{|c|c|c|c|c|c|}
\hline & $\begin{array}{l}\text { Usual care, } \\
\qquad n=29^{\mathrm{a}}\end{array}$ & $\begin{array}{c}\text { Usual care and } \\
\text { pedometer, } n=31^{\mathrm{a}}\end{array}$ & $\begin{array}{l}\text { Structured support, } \\
\qquad n=31^{\mathrm{a}}\end{array}$ & $\begin{array}{l}\text { Structured support and } \\
\text { pedometer, } n=31^{\mathrm{a}}\end{array}$ & $\begin{array}{c}\text { All, } \\
n=122^{\mathrm{a}}\end{array}$ \\
\hline Age, years, mean (SD) & $48.8(11.82)$ & $46.9(11.31)$ & $46.0(12.12)$ & $47.2(11.4)$ & $47.2(11.6)$ \\
\hline Weight, kg, mean (SD) & $97.4(16.02)$ & $93.7(15.93)$ & $99.2(18.24)$ & $103.8(19.76)$ & $98.5(17.7)$ \\
\hline Body mass index, $\mathrm{kg} / \mathrm{m}^{2}$, mean (SD) & $35.3(4.57)$ & $34.4(5.41)$ & $36.4(5.45)$ & $37.5(5.17)$ & $35.9(5.2)$ \\
\hline Waist, cm, mean (SD) & $109.4(9.76)$ & $107.9(11.8)$ & $111.0(14.7)$ & $116.0(15.5)$ & $111.1(13.4)$ \\
\hline EQ-VAS, mean (SD) & $62.6(20.7)$ & $60.4(21.2)$ & $56.3(20.1)$ & $54.2(18.7)$ & $58.3(20.2)$ \\
\hline \multicolumn{6}{|l|}{$\mathrm{EQ}-5 \mathrm{D}^{\mathrm{b}}, n(\%)$} \\
\hline Mobility, some problems & $13(44.8)$ & 7 (23.3) & $8(27.6)$ & $12(38.7)$ & $40(33.6)$ \\
\hline Self-care, some problems & $1(3.4)$ & $1(3.3)$ & $1(3.6)$ & $3(9.7)$ & $6(5.1)$ \\
\hline Usual activities, some problems/unable & $11(37.9)$ & $6(20.0)$ & $6(20.7)$ & $10(32.3)$ & $33(27.7)$ \\
\hline Pain and discomfort, moderate/extreme & $21(72.4)$ & $15(50.0)$ & $15(51.7)$ & $21(67.8)$ & $72(60.5)$ \\
\hline Anxiety and depression, moderate/extreme & $11(37.9)$ & $16(53.3)$ & $16(55.2)$ & $19(61.3)$ & $62(52.1)$ \\
\hline \multicolumn{6}{|l|}{ Medical history, $n(\%)$} \\
\hline Hypertension & $9(31.0)$ & $9(30.0)$ & $12(38.7)$ & $14(45.2)$ & $44(37.0)$ \\
\hline Asthma & $4(13.8)$ & $7(22.6)$ & $5(16.1)$ & $8(25.8)$ & $24(19.7)$ \\
\hline Back pain & $14(48.3)$ & $12(38.7)$ & $15(48.4)$ & $19(61.3)$ & $60(49.2)$ \\
\hline Sleep apnoea & $2(6.9)$ & $3(9.7)$ & $2(6.7)$ & $4(12.9)$ & $11(9.1)$ \\
\hline Mental health problem & $6(20.7)$ & $5(16.1)$ & $7(22.6)$ & $8(25.8)$ & $26(21.3)$ \\
\hline Other chronic condition & $4(16.7)$ & $7(26.9)$ & $6(26.1)$ & $4(20.0)$ & $21(22.6)$ \\
\hline Current smoker, $n(\%)$ & $6(20.7)$ & $8(25.8)$ & $5(16.1)$ & $2(6.4)$ & $21(17.2)$ \\
\hline \multicolumn{6}{|l|}{ Demographic details, $n(\%)$} \\
\hline Female & $24(83)$ & $26(84)$ & $24(77)$ & $24(77)$ & $98(80.3)$ \\
\hline Married/cohabiting & $22(75.9)$ & $23(76.7)$ & $23(82.1)$ & $23(74.2)$ & $91(77.1)$ \\
\hline No qualifications & $9(31.0)$ & $8(27.6)$ & $6(21.4)$ & $8(27.6)$ & $31(27.0)$ \\
\hline Employed & $16(55.2)$ & $14(46.7)$ & $18(64.3)$ & $23(74.2)$ & $71(60.2)$ \\
\hline
\end{tabular}

${ }^{a}$ Numbers of participants vary for each variable depending on missing values. ${ }^{\mathrm{b}}$ Reporting any problem. EQ-VAS $=$ EuroQol Visual Analogue Scale. EQ-5D $=$ EuroQol - 5 dimensions. 


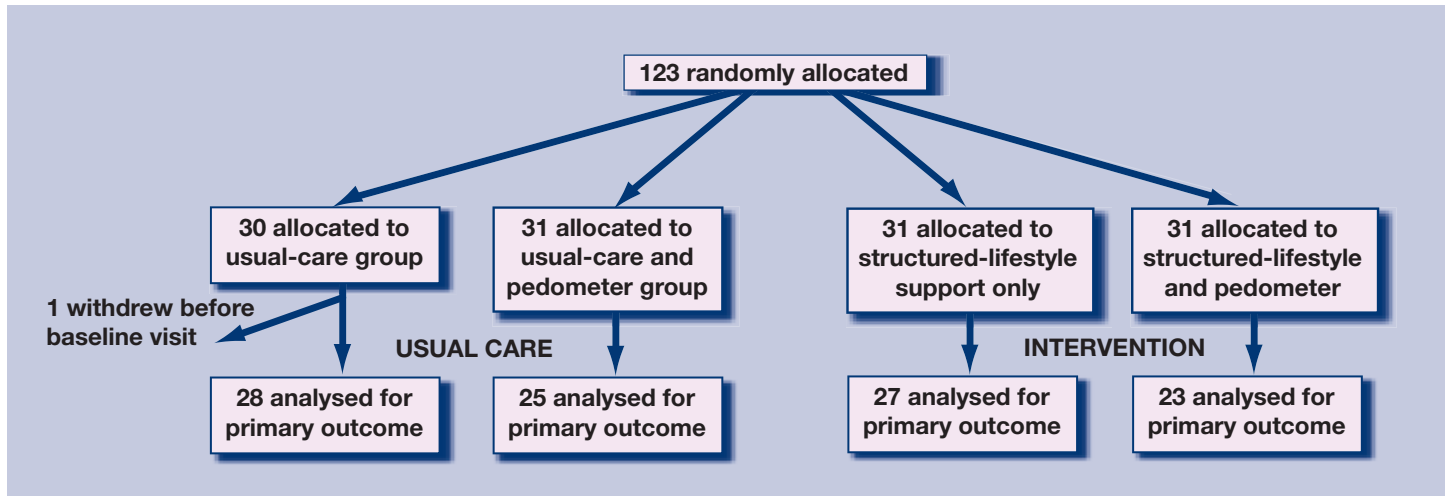

Figure 1. Participant flow.

age $=40.7$ and 48.4 years respectively; $P=0.007$ ).

\section{Outcomes}

The adjusted mean difference in weight in the structured support compared to usual care groups was $-2.63 \mathrm{~kg}(95 \% \mathrm{Cl}=-4.06$ to $-1.20 \mathrm{~kg})$, and in the pedometer compared to no pedometer group it was $-0.11 \mathrm{~kg}(95 \% \mathrm{Cl}=-1.52$ to $1.30 \mathrm{~kg}$; Table 2$)$.

One in three $(17 / 50,34.0 \%)$ participants in the structured support group lost $5 \%$ or more of their baseline weight compared to fewer than one in five $(10 / 53,18.9 \%)$ in the usual-care group; provision of a pedometer made little difference $(14 / 48,29.2 \%$ pedometer group; $13 / 55,23.6 \%$ no pedometer group). Assuming those lost to follow-up lost less than $5 \%$ would reduce these proportions somewhat (structured support: 17/61, 27.4\%; usual care: 10/61, 16.4\%; pedometer: 14/62, 22.6\%; no pedometer: $13 / 61,21.3 \%)$. Structured support resulted in a greater percentage weight loss than did usual care (adjusted difference mean $-2.78 \% ; 95 \% \mathrm{Cl}=-4.25$ to $-1.30 \%$ ); provision of a pedometer did not affect the degree of weight loss (adjusted difference mean $-0.36 \% ; 95 \% \mathrm{Cl}=-1.82$ to $1.10 \%$; Table 2).

The difference in waist circumference change between the structured support and usual-care groups was $-1.80 \mathrm{~cm}(95 \% \mathrm{Cl}=-3.39$ to $-0.20 \mathrm{~cm})$, and between the pedometer group and no pedometer groups it was $-0.84 \mathrm{~cm}(95 \% \mathrm{Cl}=-2.42$, $0.73 \mathrm{~cm}$; Table 2).

There was a trend for increasing improvement in blood pressure with increasing degree of weight loss (Appendix 2).

Weight loss was associated with improvement in weight-related quality of life, self-esteem, and health status; and decrease in weight-related symptoms, degree of their 'bothersome-ness', depression, and anxiety (Appendix 3). The level of change tended to

Table 2. Effect of the intervention on weight and waist circumference.

\begin{tabular}{|c|c|c|c|c|}
\hline & \multicolumn{2}{|c|}{ Structured support } & \multicolumn{2}{|c|}{ Pedometer } \\
\hline & No & Yes & No & Yes \\
\hline Participants, $n$ & 53 & 50 & 55 & 48 \\
\hline \multicolumn{5}{|l|}{ Weight, kg } \\
\hline Baseline visit, mean (SD) & $94.13(16.06)$ & $101.0(18.60)$ & $97.84(17.36)$ & $97.03(18.03)$ \\
\hline Final visit, mean (SD) & $92.96(16.13)$ & $97.03(18.45)$ & $95.31(16.41)$ & $94.51(18.50)$ \\
\hline Change: final-follow-up, mean (SD) & $-1.17(3.84)$ & $-3.96(3.47)$ & $-2.53(3.88)$ & $-2.52(3.98)$ \\
\hline Adjusted difference ${ }^{a}$, mean $(95 \% \mathrm{Cl})$ & & $-2.63(-4.06$ to -1.20$)$ & & $-0.11(-1.52$ to 1.30$)$ \\
\hline \multicolumn{5}{|l|}{ Weight loss, \% } \\
\hline Final visit, mean (SD) & $-1.20(4.06)$ & $-3.96(3.40)$ & $-2.42(3.96)$ & $-2.69(4.05)$ \\
\hline Adjusted difference ${ }^{a}$, mean $(95 \% \mathrm{Cl})$ & & $-2.78(-4.25$ to -1.30$)$ & & $-0.36(-1.82$ to 1.10$)$ \\
\hline \multicolumn{5}{|l|}{ Weight change, $n$ (\%) } \\
\hline Lost $\geq 5 \%$ & $10(18.9)$ & $17(34.0)$ & $13(23.6)$ & $14(29.2)$ \\
\hline Lost $0-5 \%$ & $23(43.4)$ & $27(54.0)$ & $29(52.7)$ & $21(43.8)$ \\
\hline Gained weight & $20(37.7)$ & $6(12.0)$ & $13(23.6)$ & $13(27.1)$ \\
\hline \multicolumn{5}{|l|}{ Waist circumference ${ }^{\mathrm{b}}, \mathrm{cm}$} \\
\hline Baseline visit, mean (SD) & $108.0(11.15)$ & $113.5(15.11)$ & $110.1(13.05)$ & $111.2(13.94)$ \\
\hline Final visit, mean (SD) & $106.6(12.15)$ & $110.3(15.62)$ & $108.1(12.91)$ & $108.6(15.23)$ \\
\hline Change: final-follow-up, mean (SD) & $-1.41(4.68)$ & $-3.19(3.50)$ & $-1.99(3.66)$ & $-2.57(4.82)$ \\
\hline Adjusted difference ${ }^{a}$, mean $(95 \% \mathrm{Cl})$ & & $-1.80(-3.39$ to -0.20$)$ & & $-0.84(-2.42$ to 0.73$)$ \\
\hline
\end{tabular}

${ }^{a}$ Difference in change between the intervention and its control group adjusted for age, sex, value at baseline, and the other intervention. ${ }^{b}$ Value for waist circumference missing for one person. Negative differences represent a favourable outcome. 
Table 3. Participants' views on elements of the nurse-led structured support $(n=45)^{a}$.

\begin{tabular}{lccccc} 
& $\begin{array}{c}\text { Not at all helpful, } \\
n(\%)\end{array}$ & $\begin{array}{c}\text { Not helpful, } \\
n(\%)\end{array}$ & $\begin{array}{c}\text { Neutral, } \\
n(\%)\end{array}$ & $\begin{array}{c}\text { Very helpful, } \\
n(\%)\end{array}$ & $\begin{array}{c}\text { Extremely helpful, } \\
n(\%)\end{array}$ \\
\hline Discussing weight goal & - & - & $8(17.8)$ & $24(53.3)$ & $13(28.9)$ \\
\hline Agreeing lifestyle changes & - & - & $4(8.9)$ & $29(64.4)$ & $12(26.7)$ \\
\hline Tracking lifestyle changes & - & $1(2.2)$ & $8(17.8)$ & $23(51.1)$ & $13(28.9)$ \\
\hline Receiving meal suggestions & $1(2.2)$ & $6(13.3)$ & $10(22.2)$ & $18(40.0)$ & $10(22.2)$ \\
\hline Developing eating plan & - & $4(9.3)$ & $12(27.9)$ & $14(32.6)$ & $13(30.2)$ \\
\hline Receiving weight printout & $2(4.6)$ & $2(4.6)$ & $7(16.3)$ & $15(34.9)$ & $17(39.5)$ \\
\hline Kick-start handout & - & $4(9.1)$ & $12(27.3)$ & $18(40.9)$ & $10(22.7)$ \\
\hline Eating plan handout & $3(6.7)$ & $4(8.9)$ & $12(26.7)$ & $18(40.0)$ & $8(17.8)$ \\
\hline Physical activity handout & - & $3(6.7)$ & $14(31.1)$ & $18(40.0)$ & $10(22.2)$ \\
\hline Computer-led motivation & $2(4.6)$ & $2(4.6)$ & $10(23.3)$ & $19(44.2)$ & $10(23.3)$ \\
\hline Computer weight loss chart & - & $5(11.1)$ & $9(20.0)$ & $19(42.2)$ & $12(26.7)$ \\
\hline Computer feedback & - & $3(6.7)$ & $8(17.8)$ & $20(44.4)$ & $14(31.1)$ \\
\hline
\end{tabular}

aFive of 50 in the structured support group who were successfully followed up did not complete this section of the questionnaire.

be related to degree of weight loss.

The majority of participants reported finding structured support very or extremely helpful, particularly agreeing lifestyle goals (Table 3). While the majority of participants said they benefited from participation, a higher proportion in the structuredsupport groups reported satisfaction with level of weight loss, meeting their expectations, and achieving their goals (Table 4). The majority of participants in the pedometer group reported using the pedometer every day $(28 / 44,63.6 \%)$, or on most days $(15 / 44,34.1 \%)$. A majority of participants $(55 / 97,56.7 \%)$ said they would like to return monthly for continuing support.

\section{Process evaluation}

Participants were asked open-ended questions to ascertain their views on study participation. Benefits mentioned included: "knowing I was going to be weighed', 'pedometer encouraging extra exercise, setting daily goals', 'more aware of food quantities', and 'encouragement from the nurse'. They found that participation 'changed my lifestyle totally', 'gave me focus-identified issues I could improve', 'made me walk more', '[gave me a] good feeling to see graphs going down on computer', and 'gave me definite goal and deadline'. Participants particularly liked 'being weighed regularly and getting support' and being 'able to talk to someone'. Some participants would prefer 'being weighed every week', 'calorie-counted recipes', and 'info on exercise classes'. Personal illness, family circumstances, and holidays were reported as things that got in the way of participation. Participants would have liked to have lost more weight. Pedometers were helpful as 'I realised how little I was active' and '[it] spurred me on to walk more', although some found it 'uncomfortable to wear - often dislodged', said it 'got tiresome after a while' and 'kept forgetting to put it on first thing'.

\section{DISCUSSION}

\section{Summary of main findings}

While this study was not powered to compare differences in weight loss, the level achieved was a mean of $4.0 \mathrm{~kg}$ over 12 weeks for participants randomised to receive structured support compared to $1.2 \mathrm{~kg}$ in those receiving usual care. One-third $(34.0 \%)$ of participants in the structured-support group achieved a clinically meaningful weight loss of $5 \%$ or more.

\section{Strengths and limitations of the study}

A few studies have reported weight reduction as a

Table 4. Participants' views on taking part in the trial.

\begin{tabular}{lcccc} 
& $\begin{array}{c}\text { Usual } \\
\text { care }\end{array}$ & $\begin{array}{c}\text { Usual care and } \\
\text { pedometer }\end{array}$ & $\begin{array}{c}\text { Structured } \\
\text { support }\end{array}$ & $\begin{array}{c}\text { Structured } \\
\text { support and pedometer }\end{array}$ \\
\hline Participants, $n$ & 27 & 24 & 27 & 23 \\
\hline Satisfied with weight loss, $n(\%)$ & $5(18.5)$ & $6(25.0)$ & $14(53.8)$ & $11(57.9)$ \\
\hline Benefited by participation, $n(\%)$ & $17(63.0)$ & $21(87.5)$ & $24(92.3)$ & $21(95.4)$ \\
\hline Met expectations, $n(\%)$ & $4(16.0)$ & $6(25.0)$ & $14(58.3)$ & $11(52.4)$ \\
\hline Helpful in achieving goals, $n(\%)$ & $7(29.2)$ & $9(39.1)$ & $17(73.9)$ & $19(86.4)$ \\
\hline
\end{tabular}


result of interventions in some patients, ${ }^{17-19}$ but interventions in this field are largely limited to obese patients or to overweight patients with comorbidities. This is the first study providing evidence for the feasibility of an randomised controlled trial for weight management in primary care, developed using a complex interventions strategy recommended by the MRC, and following the National Institute for Health and Clinical Excellence (NICE) guidance on the prevention, identification, assessment, and management of overweight and obesity. ${ }^{20}$ While the NICE guidelines provide a broad foundation, this study has developed a detailed programme of personalised advice and demonstrated its feasibility in primary care.

A cost-effectiveness analysis of the intervention was not carried out, nor did the study address the increased workload for nurses in general practice. Missing values were also excluded from the analysis rather than using multiple imputation methods. ${ }^{21}$ These aspects will be addressed in a full trial.

Intervention group entry was delayed until after control group follow-up to avoid contamination. This could introduce bias between groups if there were seasonal differences in weight or public health campaigns, although the difference in time was short. Any such bias could be avoided by a cluster randomised trial design, although contamination may be small and more than counterbalanced by the increased statistical power of an individually randomised trial.

Participants may have been selected or selfreferred on keenness to lose weight, which is likely to reflect the type of patient presenting in general practice for advice on weight management.

\section{Comparison with existing literature}

The degree of weight loss achieved in this study was similar to the $3.34 \mathrm{~kg}$ average loss at 3 months in the Counterweight observational study, ${ }^{22}$ conducted in UK general practice. One-third of participants in the structured support group achieved clinically meaningful weight loss of $5 \%$, compared to onequarter in Counterweight. ${ }^{22}$ Similar levels have been reported from trials in primary care in US African-American women, ${ }^{23}$ and for overweight patients with hypertension in Finland. ${ }^{24}$ The present study achieved a follow-up rate of $84.4 \%$ compared to $54.6 \%$ at 3 months in Counterweight. ${ }^{22}$

Exercise appears to be the component of treatment most likely to promote long-term maintenance of reduced weight. ${ }^{25,26}$ Participants using a pedometer in this study lost an average of $2.5 \mathrm{~kg}$, which was similar to those with no pedometer. However, patientcentred counselling in primary care has reportedly led to increased physical activity, ${ }^{27}$ and been associated with reduced weight, blood pressure, and cholesterol. ${ }^{28}$ A systematic review of studies using pedometers to increase physical activity and improve health showed an association with significant increase in physical activity of $26.9 \%$ above baseline, and significant decreases in BMI and blood pressure. ${ }^{29}$ A meta-analysis of pedometer-based walking programmes reported modest weight loss of $0.05 \mathrm{~kg}$ per week, with longer programmes leading to greater weight loss than shorter ones. ${ }^{30}$

Wider objectives of management of overweight and obesity such as optimising lipids, glycaemic control, and blood pressure, may be achieved by modest weight loss of $5-10 \%$, improved nutrition, and modest increases in physical activity. ${ }^{31}$ Two recent reviews of randomised controlled trials in patients with hypertension or pre-diabetes reported such benefits from modest weight loss. ${ }^{32,33}$ Some effect on blood pressure, related to the degree of weight loss, was observed in the present study.

The high proportion of participants reporting anxiety and depression and problems with mobility, self-care, and carrying out usual activities reported here, has been observed by others; for example, raised $\mathrm{BMI}$ was associated with increased risk of depression in a cohort study conducted in Norway, ${ }^{34}$ and has been associated with lower health-related quality of life in the UK ${ }^{35}$ and US. ${ }^{36}$ In the present study, weight loss was related to reduction in anxiety and depression, and improvement in weight-related symptoms, self-esteem, and quality of life. Similar relationships have been reported for health-related quality of life ${ }^{16}$ and self-esteem. ${ }^{37}$

Healthcare professionals in general practice are often reluctant to counsel patients on weight management because of the perceived need for additional training. ${ }^{11}$ Nurses in the present study did receive training, and the majority of participants receiving structured support found study participation helpful in achieving their goals.

\section{Implications for clinical practice}

Obesity is significantly related to increased use of primary care and diagnostic services in the US,,$^{38}$ use of outpatient services and medical prescriptions in the $U K,{ }^{39}$ and increasing use of anti-obesity medication. ${ }^{40,41}$ The UK government aims to reverse the rising tide of obesity and overweight in the population. ${ }^{42}$ This study has developed an intervention, following guidelines recommended by $\mathrm{NICE},{ }^{20}$ and shown its implementation to be feasible in primary care. NICE guidelines stress the urgent need for well-designed randomised controlled trials to address the effects of non-pharmacological interventions and to evaluate multi-component interventions in primary care. The programme outlined here is now being evaluated in a fully 
powered long-term randomised controlled trial that includes cost-effectiveness and process evaluation.

\section{Funding body}

The work was supported by grants from the British Heart Foundation (PG/04/001) and the Department of Health

\section{Ethical approval}

Ethical approval was obtained from the North West of England MREC (05/MRE08/27), relevant local ethics committees, and the London School of Hygiene \& Tropical Medicine ethics committee

\section{Competing interests}

The authors have stated that there are none

\section{Acknowledgements}

We would like to thank the study participants; the nurses who implemented the study (Anna Baker, Lynn Crombie, Barbara Cunningham, Ursula Evans, Monica Lloyd, Clare Nicolle, Kate O'Brien, Hazel Price); members of the advisory group (Professor Philip James, Dr Susan Jebb, Professor Anthony Kessel, Dr Colin Waine, Dr Leslie Wilkie, Dr Paul Wilkinson); and Sandy Evans (KasTech) for contributing to the nurse training; and the senior nursing team (Kay Foulger and Nicky Fasey) at the GPRF coordinating centre.

\section{Discuss this article}

Contribute and read comments about this article on the Discussion Forum: http://www.rcgp.org.uk/bjgp-discuss

\section{REFERENCES}

1. James WPT. The epidemiology of obesity: the size of the problem. $J$ Intern Med 2008; 263(4): 336-352.

2. The NHS Information Centre. Statistics on obesity, physical activity and diet: England, January 2008. The NHS Information Centre, 2008.

3. Foresight. Tackling obesities: future choices — project report. London: Foresight, 2007.

4. House of Commons Health Committee. Obesity. London: The House of Commons, 2003-2004; 1-146.

5. General Controller and Auditor. Tackling obesity in England. London: House of Commons, 2000-2001; 1-6.

6. Department of Health. Choosing health: making healthy choices easier. London: The Stationery Office, 2004.

7. Wardle J, Johnson, F. Weight and dieting: examining levels of weight concern in British adults. Int J Obes Relat Metab Disord 2002; 26(8): 1144-1149.

8. Coffield A, Maciosek M, McGinnis J, et al. Priorities among recommended clinical preventive services. Am J Prev Med 2001; 21(1): $1-9$.

9. Campbell M, Fitzpatrick R, Haines A, et al. Framework for design and evaluation of complex interventions to improve health. $B M J 2000$; 321(7262): 694-696.

10. Nanchahal K, Townsend J, Haslam D, et al. Weight management in general practice: survey of general practitioners and nurses in the UK. Int J Obes 2007; 31: S121. http://www.nature.com/ijo/journal/ v31/n1s/abs/0803598a.html (accessed 2 Apr 2009).

11. Nanchahal K, Hirani V, Townsend J, et al. Weight management in general practice: views of patients, nurses and general practitioners in the UK. Int J Obes 2007; 31: S193. http://www.nature.com/ijo/journal/ v31/n1s/abs/0803599a.html (accessed 2 Apr 2009).

12. Whitlock EP, Orleans CT, Pender N, Allan J. Evaluating primary care behavioral counseling interventions: an evidence-based approach. Am J Prev Med 2002; 22(4): 267-284.

13. Rosenberg M. Society and the adolescent self image. Princeton, NJ: Princeton University Press, 1965.

14. Bjelland I, Dahl AA, Haug TT, Neckelmann D. The validity of the Hospital Anxiety and Depression Scale: an updated literature review. J Psychosom Res 2002; 52(2): 69-77.

15. Rabin R, de Charro F. EQ-5D: a measure of health status from the EuroQol Group. Ann Med 2001; 33(5): 337-343.

16. Patrick DL, Bushnell DM, Rothman M. Performance of two self-report measures for evaluating obesity and weight loss. Obes Res 2004; 12(1): $48-57$.

17. Kirk SF, Harvey EL, McConnon A, et al. A randomised trial of an Internet weight control resource: the UK Weight Control Trial [ISRCTN58621669]. BMC Health Serv Res 2003; 3(1): 19.
18. Laws R. A new evidence-based model for weight management in primary care: the Counterweight Programme. J Hum Nutr Diet 2004; 17(3): 191-208.

19. Greaves CJ, Middlebrooke A, O'Loughlin L, et al. Motivational interviewing for modifying diabetes risk: a randomised controlled trial. Br J Gen Pract 2008; 58(553): 535-540.

20. National Institute for Health and Clinical Excellence. Guidance on the prevention, identification, assessment, treatment and weight managemen of overweight and obesity in adults and children. London: NICE, 2006.

21. Kenward MG, Carpenter J. Multiple imputation: current perspectives. Stat Methods Med Res 2007; 16(3): 199-218.

22. Ross H, Laws R, Reckless J, Lean M. Evaluation of the Counterweight Programme for obesity management in primary care: a starting point for continuous improvement. Br J Gen Pract 2008; 58(553): 548-554.

23. Davis Martin P, Rhode PC, Dutton GR, et al. A primary care weight management intervention for low-income African-American women. Obesity 2006; 14(8): 1412-1420.

24. Jalkanen $\mathrm{L}$. The effect of a weight reduction program on cardiovascular risk factors among overweight hypertensives in primary health care. Scand J Soc Med 1991; 19(1): 66-71.

25. Avenell A, Brown TJ, McGee MA, et al. What interventions should we add to weight reducing diets in adults with obesity? A systematic review of randomized controlled trials of adding drug therapy, exercise, behaviour therapy or combinations of these interventions. $J$ Hum Nutr Diet 2004; 17(4): 293-316.

26. Catenacci VA, Wyatt HR. The role of physical activity in producing and maintaining weight loss. Nat Clin Pract Endocrinol Metab 2007; 3(7): 518-529.

27. Hardcastle S, Taylor A, Bailey M, Castle R. A randomised controlled trial on the effectiveness of a primary health care based counselling intervention on physical activity, diet and CHD risk factors. Patient Educ Couns 2008; 70(1): 31-39.

28. Steptoe A, Rink E, Kerry S. Psychosocial predictors of changes in physical activity in overweight sedentary adults following counseling in primary care. Prev Med 2000; 31(2): 183-194.

29. Bravata DM, Smith-Spangler C, Sundaram V, et al. Using pedometers to increase physical activity and improve health: a systematic review. JAMA 2007; 298(19): 2296-2304.

30. Richardson CR, Newton TL, Abraham JJ, et al. A meta-analysis of pedometer-based walking interventions and weight loss. Ann Fam Med 2008; 6(1): 69-77.

31. Tsigos C, Hainer V, Basdevant A, et al. Management of obesity in adults: European clinical practice guidelines. Obesity Facts 2008; 1 (2): 106-116.

32. Mulrow CD, Chiquette E, Angel L, et al. Dieting to reduce body weight for controlling hypertension in adults. Cochrane Database Syst Rev 2002; 2: CD000484.

33. Norris SL, Zhang X, Avenell A, et al. Long-term effectiveness of weightloss interventions in adults with pre-diabetes: a review. Am J Prev Med 2005; 28(1): 126-39.

34. Bjerkeset O, Romundstad P, Evans J, Gunnell D. Association of adult body mass index and height with anxiety, depression, and suicide in the general population: the HUNT Study. Am J Epidemiol 2008; 167(2): 193-202.

35. Sach TH, Barton GR, Doherty M, et al. The relationship between body mass index and health-related quality of life: comparing the EQ-5D, EuroQol VAS and SF-6D. Int J Obes 2006; 31(1): 189-196.

36. Jia H, Lubetkin EI. The impact of obesity on health-related quality-oflife in the general adult US population. J Public Health 2005; 27(2): 156-164.

37. Blaine BE, Rodman J, Newman JM. Weight loss treatment and psychological well-being: a review and meta-analysis. J Health Psychol 2007; 12(1): 66-82.

38. Bertakis KD, Azari R. Obesity and the use of health care services. Obes Res 2005; 13(2): 372-379.

39. Popoola FA. Increase in obesity and health-care use, from the Health Survey for England, ages 50 to 69, 1998. Obes Surg 2004; 14(9): 1258-1262.

40. Srishanmuganathan J, Patel H, Car J, Majeed A. National trends in the use and costs of anti-obesity medications in England 1998-2005. J Public Health 2007; 29(2): 199-202.

41. Stafford RS, Radley DC. National trends in antiobesity medication use Arch Intern Med 2003; 163(9): 1046-1050.

42. Department of Health. Healthy weight, healthy lives: a cross government strategy for England. London: Department of Health, 2008. 


\section{Appendix 1. Structured programme overview.}

\begin{tabular}{|c|c|c|}
\hline Week & Session & Handout \\
\hline 0 & $\begin{array}{l}\text { Introduction and initial assessment } \\
\text { Take measurements (height, weight, waist circumference, blood pressure) } \\
\text { Discuss motivations for losing weight, lifestyle changes } \\
\text { Set a } 5 \% \text { weight-loss goal }\end{array}$ & $\begin{array}{l}\text { 7-day sample meal plan } \\
\text { Blank food diary } \\
\text { Standard fortnightly lifestyle goals }\end{array}$ \\
\hline 2 & $\begin{array}{l}\text { Food choices and eating habits } \\
\text { Weigh, show graph, and review progress } \\
\text { Discuss specific eating changes and devise eating plan } \\
\text { Review previous dieting efforts and outcomes } \\
\text { Discuss support from family and friends } \\
\text { Agree three personalised lifestyle goals }\end{array}$ & $\begin{array}{l}\text { Patient information sheet: key ways to kick-start } \\
\text { healthier habits } \\
\text { Personalised fortnightly lifestyle goals } \\
\text { Meal plan/snack suggestion }\end{array}$ \\
\hline 4 & $\begin{array}{l}\text { Activity goal setting and health benefits } \\
\text { Weigh, show graph, and review progress } \\
\text { Devise personalised activity programme and energy expenditure goal } \\
\text { Discuss health benefits with increasing activity }\end{array}$ & $\begin{array}{l}\text { Weight graph } \\
\text { Patient information sheet: healthy reasons } \\
\text { to exercise } \\
\text { Fortnightly activity programme to monitor }\end{array}$ \\
\hline 8 & $\begin{array}{l}\text { Identifying and managing obstacles } \\
\text { Weigh, show graph, and review progress } \\
\text { Identify and discuss difficulties and some initial ideas or solutions for dealing with them } \\
\text { Identify helpful rewards and family, friends, work, and community support available }\end{array}$ & $\begin{array}{l}\text { Weight graph } \\
\text { Personalised monthly lifestyle goals } \\
\text { Meal plan/snack suggestion }\end{array}$ \\
\hline 12 & $\begin{array}{l}\text { Programme review and reassessment } \\
\text { Weigh, show graph, and review progress } \\
\text { Reinforce achievements and discuss lifestyle goals and importance of monitoring } \\
\text { Briefly discuss time management, value of scheduling appointments, and relaxation } \\
\text { Highlight any ongoing community and practice resources and support available }\end{array}$ & $\begin{array}{l}\text { Weight graph } \\
\text { Certificate of achievement } \\
\text { Personalised monthly lifestyle goals }\end{array}$ \\
\hline
\end{tabular}




\begin{tabular}{|c|c|c|c|}
\hline & & ercentage weight chan & \\
\hline & $\geq 5 \%$ loss & 0 to $<5 \%$ loss & Gain \\
\hline Participants, $n^{\mathrm{b}}$ & 27 & 50 & 26 \\
\hline Weight change, \%, mean (SD) & $-7.45(1.88)$ & $-2.53(1.53)$ & $2.54(1.90)$ \\
\hline $\begin{array}{l}\text { Systolic blood pressure, } \mathrm{mmHg} \\
\text { Baseline, mean (SD) } \\
\text { Final, mean (SD) } \\
\text { Difference ( } 95 \% \mathrm{Cl})\end{array}$ & $\begin{array}{c}136.6(15.86) \\
126.2(13.87) \\
-10.0(-15.5 \text { to }-4.5)\end{array}$ & $\begin{array}{c}131.1(18.97) \\
126.6(15.51) \\
-4.5(-8.8 \text { to }-0.24)\end{array}$ & $\begin{array}{c}135.5(24.84) \\
133.2(19.11) \\
-2.4(-11.4 \text { to } 6.6) \\
\end{array}$ \\
\hline $\begin{array}{l}\text { Diastolic blood pressure (mmHc } \\
\text { Baseline, mean (SD) } \\
\text { Final, mean (SD) } \\
\text { Difference ( } 95 \% \mathrm{Cl}) \\
\end{array}$ & $\begin{array}{c}83.4(9.10) \\
77.3(7.33) \\
-6.2(-8.9 \text { to }-3.4) \\
\end{array}$ & $\begin{array}{c}77.4(10.41) \\
76.0(9.86) \\
-1.4(-4.0 \text { to } 1.2) \\
\end{array}$ & $\begin{array}{c}83.5(10.04) \\
81.8(8.62) \\
-1.6(-6.2 \text { to } 2.9) \\
\end{array}$ \\
\hline $\begin{array}{l}\text { Fasting glucose, mmol/L } \\
\text { Baseline, mean (SD) } \\
\text { Final, mean (SD) } \\
\text { Difference (95\% Cl) }\end{array}$ & $\begin{array}{c}5.17(0.51) \\
5.09(0.57) \\
-0.08(-0.28 \text { to } 0.11) \\
\end{array}$ & $\begin{array}{c}5.41(1.14) \\
5.21(1.08) \\
-0.20(-0.42 \text { to } 0.03)\end{array}$ & $\begin{array}{c}5.24(0.75) \\
5.41(0.90) \\
0.17(-0.21 \text { to } 0.56) \\
\end{array}$ \\
\hline $\begin{array}{l}\text { Total cholesterol, mmol/L } \\
\text { Baseline, mean (SD) } \\
\text { Final, mean (SD) } \\
\text { Difference }(95 \% \mathrm{Cl}) \\
\end{array}$ & $\begin{array}{c}5.21(1.26) \\
4.99(1.11) \\
-0.23(-0.61 \text { to } 0.15) \\
\end{array}$ & $\begin{array}{c}4.91(1.15) \\
5.10(1.09) \\
0.19(-0.08 \text { to } 0.47) \\
\end{array}$ & $\begin{array}{c}4.84(1.12) \\
4.80(1.26) \\
-0.04(-0.42 \text { to } 0.35) \\
\end{array}$ \\
\hline $\begin{array}{l}\text { HDL cholesterol, } \mathrm{mmol} / \mathrm{L} \\
\text { Baseline, mean (SD) } \\
\text { Final, mean (SD) } \\
\text { Difference }(95 \% \mathrm{Cl})\end{array}$ & $\begin{array}{c}1.31(0.40) \\
1.36(0.33) \\
0.05(-0.07 \text { to } 0.17) \\
\end{array}$ & $\begin{array}{c}1.40(0.34) \\
1.41(0.39) \\
0.01(-0.05 \text { to } 0.07) \\
\end{array}$ & $\begin{array}{c}1.30(0.41) \\
1.33(0.44) \\
0.04(-0.09 \text { to } 0.16)\end{array}$ \\
\hline $\begin{array}{l}\text { LDL cholesterol, mmol/L } \\
\text { Baseline, mean (SD) } \\
\text { Final, mean (SD) } \\
\text { Difference (95\% Cl) } \\
\end{array}$ & $\begin{array}{c}2.89(0.97) \\
2.86(1.05) \\
-0.04(-0.49 \text { to } 0.41) \\
\end{array}$ & $\begin{array}{c}2.99(0.93) \\
3.10(0.98) \\
0.11(-0.11 \text { to } 0.33) \\
\end{array}$ & $\begin{array}{c}2.81(0.85) \\
3.01(1.17) \\
0.21(-0.18 \text { to } 0.60) \\
\end{array}$ \\
\hline $\begin{array}{l}\text { Total/HDL cholesterol ratio } \\
\text { Baseline, mean (SD) } \\
\text { Final, mean (SD) } \\
\text { Difference }(95 \% \mathrm{Cl}) \\
\end{array}$ & $\begin{array}{c}4.08(1.23) \\
3.86(1.17) \\
-0.22(-0.59 \text { to } 0.16) \\
\end{array}$ & $\begin{array}{c}3.84(0.99) \\
3.89(1.02) \\
0.06(-0.15 \text { to } 0.26) \\
\end{array}$ & $\begin{array}{c}4.13(1.60) \\
3.99(1.27) \\
-0.14(-0.64 \text { to } 0.36) \\
\end{array}$ \\
\hline $\begin{array}{l}\text { Fasting triglyceride, mmol/L } \\
\text { Baseline, mean (SD) } \\
\text { Final, mean (SD) } \\
\text { Difference }(95 \% \mathrm{Cl})\end{array}$ & $\begin{array}{c}1.69(0.65) \\
1.42(0.71) \\
-0.26(-0.57 \text { to } 0.04)\end{array}$ & $\begin{array}{c}1.52(0.95) \\
1.65(1.73) \\
0.13(-0.33 \text { to } 0.58)\end{array}$ & $\begin{array}{c}1.74(1.21) \\
1.61(0.81) \\
-0.12(-0.40 \text { to } 0.16)\end{array}$ \\
\hline
\end{tabular}

${ }^{a}$ Negative differences represent a favourable outcome. ${ }^{b}$ Number of participants varies for different variables due to missing data. $H D L=$ high-density lipoprotein. $L D L=$ low-density lipoprotein. 


\section{Appendix 3. Relationship between degree of weight loss and psychological and quality of life measures.}

\begin{tabular}{|c|c|c|c|}
\hline & & Percentage weight chang & \\
\hline & $\geq 5 \%$ loss & 0 to $<5 \%$ loss & Gain \\
\hline Participants, $n^{\mathrm{b}}$ & 27 & 50 & 26 \\
\hline Obesity and Weight-Lc & of Life & & \\
\hline Baseline, mean (SD) & $47.1(26.3)$ & $43.5(22.9)$ & $37.1(16.8)$ \\
\hline Final, mean (SD) & $51.2(26.6)$ & $46.2(24.2)$ & $36.4(18.6)$ \\
\hline Difference $(95 \% \mathrm{Cl})$ & $4.08(-2.64$ to 10.8$)$ & $2.69(-0.55$ to 5.93$)$ & $-0.68(-4.97$ to 3.61$)$ \\
\hline Weight-Related Sympt & sure - number of symp & oms & \\
\hline Baseline, mean (SD) & $8.48(5.08)$ & $7.44(4.40)$ & $8.50(4.88)$ \\
\hline Final, mean (SD) & $4.93(4.66)$ & $5.76(4.46)$ & $8.27(5.09)$ \\
\hline Difference $(95 \% \mathrm{Cl})^{\mathrm{b}}$ & $-3.56(-5.34$ to -1.78$)$ & $-1.68(-3.09$ to -0.27$)$ & $-0.23(-2.11$ to 1.64$)$ \\
\hline Weight-Related Sympt & sure - 'Bothersome-nes & ' of symptoms & \\
\hline Baseline, mean (SD) & $35.0(27.5)$ & $25.6(19.9)$ & $31.6(20.2)$ \\
\hline Final, mean (SD) & $22.9(24.2)$ & $20.2(19.9)$ & $35.2(25.4)$ \\
\hline Difference $(95 \% \mathrm{Cl})^{\mathrm{b}}$ & $-12.1(-23.5$ to -0.76$)$ & $-5.42(-10.8$ to -0.09$)$ & $3.69(-3.77$ to 11.2$)$ \\
\hline Hospital Anxiety and D & Scale - Depression & & \\
\hline Baseline, mean (SD) & $7.64(2.81)$ & $7.37(2.81)$ & $7.33(2.78)$ \\
\hline Final, mean $(\mathrm{SD})$ & $5.88(2.62)$ & $6.61(3.05)$ & $8.58(3.90)$ \\
\hline Difference $(95 \% \mathrm{Cl})^{\mathrm{b}}$ & $-1.76(-2.92$ to -0.60$)$ & $-0.76(-1.56$ to 0.04$)$ & 1.25 (0.01 to 2.49$)$ \\
\hline Hospital Anxiety and D & Scale - Anxiety & & \\
\hline Baseline, mean (SD) & $9.58(3.42)$ & $8.89(3.24)$ & $9.75(2.91)$ \\
\hline Final, mean (SD) & $8.08(3.06)$ & $8.39(3.43)$ & $9.33(2.99)$ \\
\hline Difference $(95 \% \mathrm{Cl})^{\mathrm{b}}$ & $-1.50(-2.79$ to -0.21$)$ & $-0.50(-1.35$ to 0.35$)$ & $-0.42(-1.51$ to 0.68$)$ \\
\hline Rosenberg Self-esteen & & & \\
\hline Baseline, mean (SD) & $12.4(10.3)$ & $11.3(6.52)$ & $13.4(7.65)$ \\
\hline Final, mean (SD) & $26.4(3.32)$ & $25.2(2.73)$ & $24.7(3.20)$ \\
\hline Difference $(95 \% \mathrm{Cl})$ & 14.1 (9.82 to 18.4$)$ & $13.9(12.0$ to 15.8$)$ & $11.4(7.7$ to 15.0$)$ \\
\hline EQ-VAS & & & \\
\hline Baseline, mean (SD) & $59.6(18.7)$ & $57.7(19.0)$ & $63.4(18.0)$ \\
\hline Final, mean (SD) & $71.8(14.1)$ & $67.1(18.3)$ & $58.3(24.2)$ \\
\hline Difference $(95 \% \mathrm{Cl})$ & $12.2(7.5$ to 17.0$)$ & 9.4 (3.7 to 15.1$)$ & $-5.1(-13.0$ to 2.8$)$ \\
\hline
\end{tabular}

${ }^{2}$ Numbers vary slightly for different variables due to missing data. ${ }^{\circ}$ Negative differences represent a favourable outcome. EQ-

VAS = EuroQol Visual Analogue Scale. 